\title{
Characteristics of $\operatorname{In}_{x} \mathrm{Ga}_{1-\mathrm{x}} \mathrm{N}$ based Light Emitting Diode with InGaN Barriers
}

\author{
Sakshi Mehendiratta \\ Department of Electronics and Communication \\ Engineering \\ National Institute of Technology Hamirpur \\ Himachal Pradesh, India
}

\author{
Amandeep Kaur \\ Department of Electronics and Communication \\ Engineering \\ National Institute of Technology Hamirpur \\ Himachal Pradesh, India
}

\begin{abstract}
The characteristics of blue InGaN multiple quantum well (MQW) Light Emitting Diodes (LEDs) with InGaN barriers are studied. The current-voltage (I-V) curve, Internal Quantum Efficiency (IQE), spontaneous rate are investigated. The simulation results show that the newly $\mathrm{In}_{0.15} \mathrm{Ga}_{0.85} \mathrm{~N} / \mathrm{InGaN}$ LED (Device 1) has reduced the forward voltage due to reduced energy barriers for electron and hole transport as compare to $\mathrm{In}_{0.2} \mathrm{Ga}_{0.8} \mathrm{~N} / \mathrm{InGaN}$ LED (Device 2). The Internal Quantum Efficiency ( 98.5 \%), Output Power $(\sim 1497.8 \mathrm{~W} / \mathrm{m})$ and spontaneous rate $\left(\sim 616.8 \times 10^{26}\right)$ achieved is more in case of $\mathrm{In}_{0.15} \mathrm{Ga}_{0.85} \mathrm{~N} / \mathrm{InGaN} 3-\mathrm{QW}$ LED.
\end{abstract}

\section{General Terms}

Quantum well LED, InGaN/InGaN LED.

\section{Keywords}

InGaN barriers, Light Emitting Diodes (LEDs), Multi-Quantum well structure.

\section{INTRODUCTION}

Group III- Nitrides that are GaN, InN and $\mathrm{AlN}$ and their ternaries as well as quaternaries, are considered to be one of the most significant semiconductors. Nitride semiconductor has exceptional optical and electrical properties due to which it found suitable in various applications i.e. lasers, displays, high power amplifiers, etc. As these parameters are very important in determining the utility and applicability of this class of materials to many devices so different properties based on these parameters are always a topic of discussion.

Over the past few years, people have proposed various physics mechanisms to explain the phenomenon such as Electron leakage [1-2], Auger recombination [3-4], carrier delocalization [5], polarization effect [6-7], poor hole injection efficiency [89], and the quantum confined Stark effect [10]. In [11] and [12], interband Auger processes are being gradually confirmed to be one of the most important physics mechanisms for efficiency droop in the InGaN LED, as well as possible solutions to address the interband Auger using new active region materials. The correlations between structural, electrical and optical properties of InGaN/InGaN MQWs LED structure are investigated in this paper. In addition, the piezoelectric field in InGaN quantum well layer changed by In-composition fluctuation, this turn will change the effective energy band gap across the wall. So the InGaN/InGaN MQW LED device by varying In-ratio in well is studied.

\section{DEVICE STRUCTURE}

The structure consists of a $200 \mathrm{~nm}$ thick Si-doped $\mathrm{In}_{0.001} \mathrm{GaN}_{0.999}$ layer (n-doping $=2 \times 10^{18} \mathrm{~cm}^{-3}$ ). The active region consisted of four 2.5-nm-thick $\operatorname{In}_{\mathrm{x}} \mathrm{Ga}_{1-\mathrm{x}} \mathrm{N}$ Quantum Wells (QWs), sandwiched by five 9-nm-thick InGaN barriers. On the top of the last quantum barrier, there were a $3 \mathrm{~nm}$ thick $\mathrm{Ga}_{0.999} \mathrm{AlIn}_{0.001} \mathrm{~N}$ layer, 20-nm-thick p- $\mathrm{Ga}_{0.85} \mathrm{Al}_{0.15} \mathrm{InN}$ Electron Blocking Layer (EBL) (p-doping $=3 \times 10^{19} \mathrm{~cm}^{-3}$ ) and a 150 nm-thick p-Ga ${ }_{0.999} \mathrm{AlIn}_{0.001} \mathrm{~N}$ cap layer $\left(\mathrm{p}\right.$-doping $=1 \times 10^{19} \mathrm{~cm}^{-}$ $\left.{ }^{3}\right)$. Two LEDs with different active layer, one with $\operatorname{In}_{0.15} \mathrm{Ga}_{0.85} \mathrm{~N}$ and other with $\operatorname{In}_{0.2} \mathrm{Ga}_{0.8} \mathrm{~N}$, has been studied. The properties of the LEDs were studied numerically with the Advanced Physical model of Semiconductor devices Simulation Software (APSYS)[13].

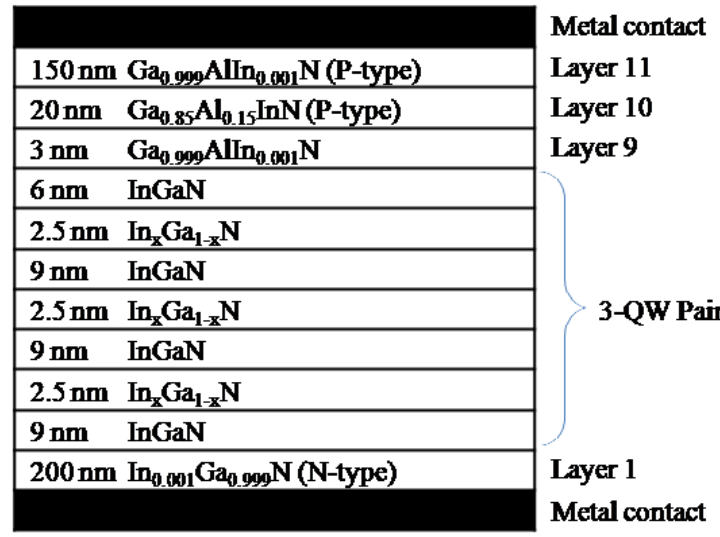

Fig 1 Schematic diagram of $\operatorname{In}_{\mathrm{X}} \mathrm{Ga}_{1-\mathrm{X}} \mathrm{N} / \mathrm{InGaN}$ QW LED Device

Fig 1 shows the schematic diagram of the $\operatorname{In}_{\mathrm{X}} \mathrm{Ga}_{1-\mathrm{X}} \mathrm{N} / \mathrm{InGaN}$ QW LED device which is taken under study by varying number of QW for two devices, one for $\mathrm{In}_{0.15} \mathrm{Ga}_{0.85} \mathrm{~N} / \mathrm{InGaN}$ QW LED and other for $\operatorname{In}_{0.2} \mathrm{Ga}_{0.8} \mathrm{~N} / \mathrm{InGaN}$ QW LED.

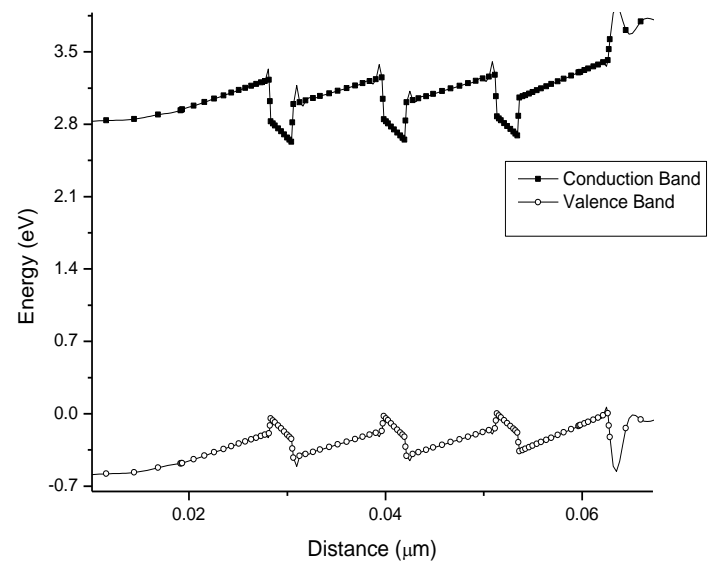

Fig 2 Energy band diagram of $\operatorname{In}_{\mathrm{X}} \mathrm{Ga}_{1-\mathrm{X}} \mathrm{N} / \mathrm{InGaN}$ QW LED Device 
Fig 2 shows energy band diagram of the $\operatorname{In}_{\mathrm{X}} \mathrm{Ga}_{1-\mathrm{X}} \mathrm{N} / \mathrm{InGaN} \mathrm{QW}$ LED device. It depicts the three quantum well formed by InGaN barrier and $\operatorname{In}_{x} \mathrm{Ga}_{1-\mathrm{x}} \mathrm{N}$ active layer. The wells are formed because of the difference in band gap energy of the active layer and barrier. The shape of well is triangular because of the polarization-induced electric field. The peak at the end of the third well shows a sudden change in the energy of the barrier and the electron blocking layer.

\section{RESULT AND DISCUSSION}

The APSYS simulation software is a device simulator based on finite-element which solves Current continuity equations, Poisson-Schrödinger equations, , heat transfer equations and hydrodynamic equations, including K.P model for MQW band structure, quantum tunnelling model for hetero junction, heat flow model for self-heating.

With the help of APSYS the simulation of $\operatorname{In}_{0.15} \mathrm{Ga}_{0.85} \mathrm{~N} / \mathrm{InGaN}$ LED (Device 1) and $\mathrm{In} 0{ }_{2} \mathrm{Ga}_{0.8} \mathrm{~N} / \mathrm{InGaN}$ LED (Device 2) by varying number of quantum well has been done and different parameters are studied. The lattice constant for different IIInitrides are shown in Table 1 . Here the bowing parameter is taken to be 1.43 .

Table $1 a$ and $c$ lattice constants and band gaps at room temperature of III- nitrides

\begin{tabular}{|c|c|c|c|}
\hline Material & $\mathbf{a}_{\mathbf{0}}(\mathbf{\AA})$ & $\mathbf{c}_{\mathbf{0}}(\mathbf{\AA})$ & $\begin{array}{c}\boldsymbol{E}_{\mathbf{g}}(\mathbf{e V}) \text { @ } \\
\mathbf{3 0 0} \mathbf{K}\end{array}$ \\
\hline $\mathrm{AlN}$ & 3.112 & 4.982 & 6.2 \\
\hline $\mathrm{GaN}$ & 3.189 & 5.185 & 3.4 \\
\hline $\mathrm{InN}$ & 3.54 & 5.718 & 0.77 \\
\hline
\end{tabular}

For $\operatorname{In}_{\mathrm{x}} \mathrm{Ga}_{1-\mathrm{x}} \mathrm{N}$ the lattice constants $a$ and $c$ can be find by using the following formula

$$
\begin{aligned}
& a=3.189(1-x)+3.54(x) \\
& c=5.185(1-x)+5.718(x)
\end{aligned}
$$

By using eqn. $1 \& 2 a$ and $c$ for $x=0.15$ is found to be 3.242 and 5.264 respectively and for $x=0.2$ these are found to be $a=$ 3.26, $c=5.291$. These lattice constants are used in the simulation.

The band gap energy for $\operatorname{In}_{\mathrm{x}} \mathrm{Ga}_{1-\mathrm{x}} \mathrm{N}$ at room temperature can be find by using eqn. 3

$$
E_{g}=(1-x) E_{g} \mathrm{GaN}+E_{g} \operatorname{InN}(x)-b * x(1-x)
$$

where $\mathrm{b}$ is the bowing parameter and is equal to 1.43

By using eqn. 3 and data from Table 1 , for $\operatorname{In}_{0.15} \mathrm{Ga}_{0.85} \mathrm{~N}$, the band gap energy, $E_{g}$ is found to be $2.84 \mathrm{eV}$ and for $\operatorname{In}_{0.2} \mathrm{Ga}_{0.8} \mathrm{~N}$, it is found to be $2.6612 \mathrm{eV}$. The wavelength corresponding to these energy band gaps can be found by using following equation.

$$
\lambda(\mathrm{nm})=\frac{1240}{E_{g}}
$$

For $\mathrm{In}_{0.15} \mathrm{Ga}_{0.85} \mathrm{~N}, \lambda=436.59 \mathrm{~nm}$ and for $\mathrm{In}_{0.2} \mathrm{Ga}_{0.8} \mathrm{~N}, \lambda=$ $465.955 \mathrm{~nm}$.

The current-voltage (I-V) curves, Internal Quantum Efficiency (IQE), Light output power and spontaneous rate of Device 1 and Device 2 is shown in the following figures.

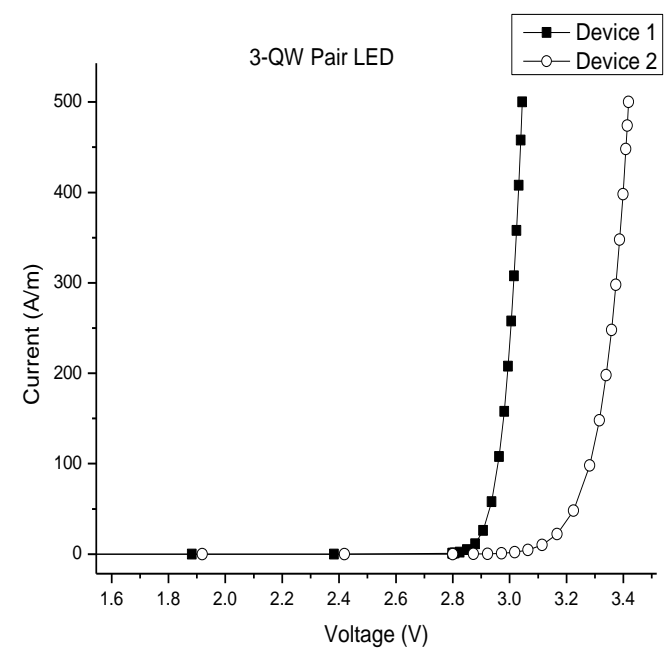

Fig 3(a) I-V characteristics comparison of 3-QW Pair LED Device 1 and Device 2

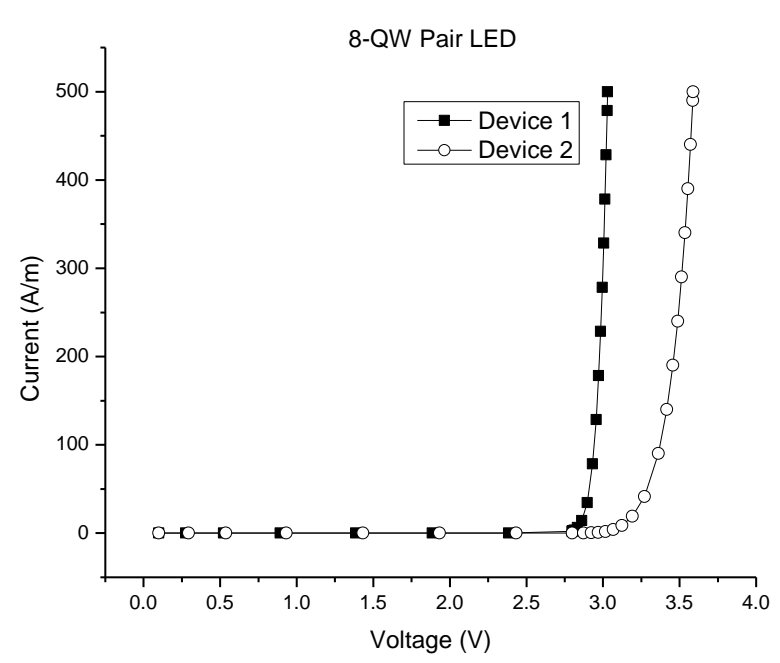

Fig 3(b) I-V characteristics comparison of 8-QW Pair LED Device 1 and Device 2

Fig 3 shows the comparison of Current-Voltage characteristics for $\operatorname{In}_{0.15} \mathrm{Ga}_{0.85} \mathrm{~N} / \mathrm{InGaN}$ LED (Device 1) and $\mathrm{In}_{0.2} \mathrm{Ga}_{0.8} \mathrm{~N} / \mathrm{InGaN}$ LED (Device 2). Fig 3(a) is comparison of device 1 and device 2 with 3-QW pair while Fig 3(b) shows for 8-QW pair device 1 and device 2. From figures it can be seen that the turn on voltage in case of device 1 is less as compare to device 2 in both the cases. With the increase in number of well the turn on voltage of device 1 decreases while that of device 2 does not show symmetrical variation. The decrease in turn on voltage is due the leakage current and it also shows that transport of carrier is improved in the device. In case of device 1 the turn on voltage is about $2.8 \mathrm{~V}$ while for device 2 it is around $3.1 \mathrm{~V}$. Depending on the application the two devices can be used. 


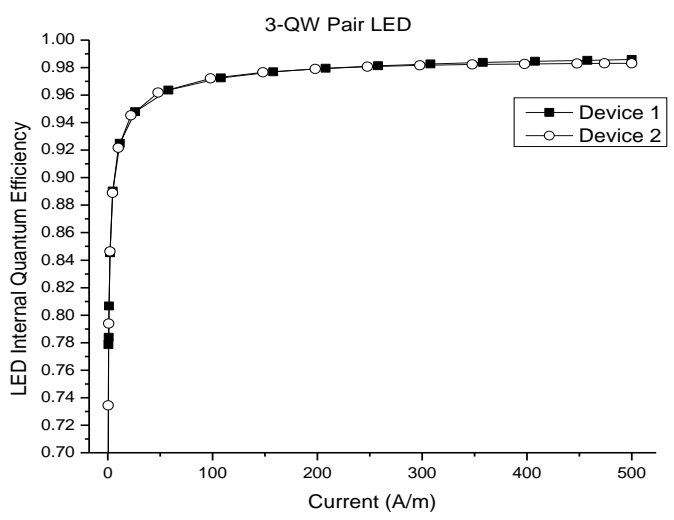

Fig 4(a) Internal Quantum Efficiency comparison of 3-QW Pair LED Device 1 and Device 2

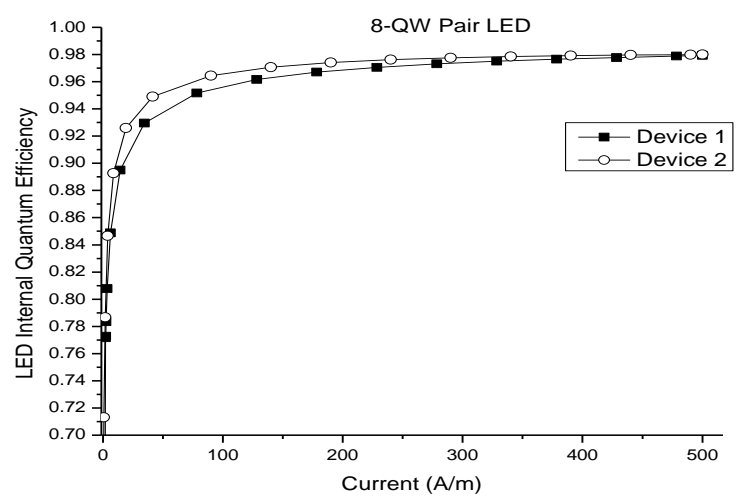

Fig 4(b) Internal Quantum Efficiency comparison of 8-QW Pair LED Device 1 and Device 2

Fig 4 shows the comparison of LED Internal Quantum Efficiency (IQE) with respect to current for Device 1 and Device 2. The figures show that peak efficiency in case of device 1 lies between 90 to $95 \%$ while for device 2 it lies between 94 to $97 \%$. It shows that for low current device 2 is achieving more efficiency as compare to device 1 and for high current both devices are achieving $\sim 98 \%$ efficiency. This increase in efficiency is due to trapping of more carriers (hole) between the last barrier (of width $6 \mathrm{~nm}$ ) from the above p-type layer. In case of device 1 the maximum achieved efficiency $(98.58 \%)$ is for 3 QW pair LED while in case of device 2 maximum efficiency $(98.569 \%)$ is achieved for 1 QW LED at high current.

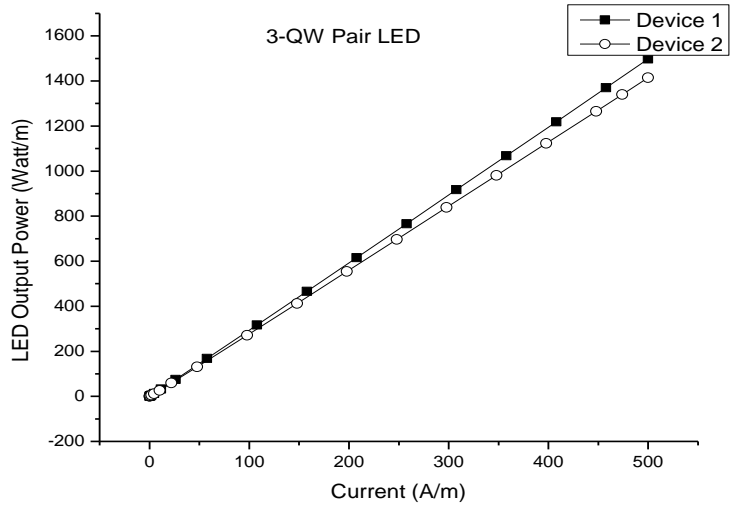

Fig 5(a) Power-current characteristics comparison of 3QW Pair LED Device 1 and Device 2

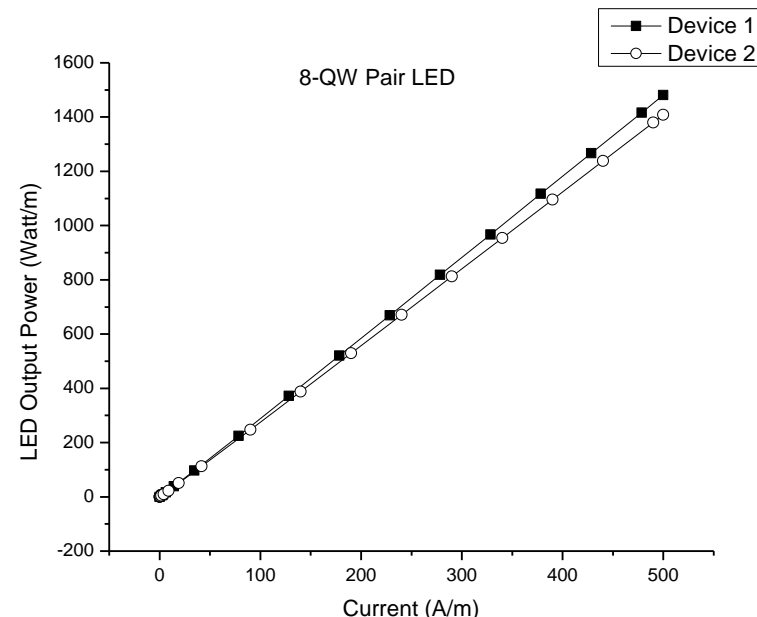

Fig 5(b) Power-current characteristics comparison of 8QW Pair LED Device 1 and Device 2

Fig 5 shows the LED output power with respect to current for Device 1 and Device 2. Both devices show linear characteristics and this linearity is important for modulation in analog transmission. From the figures it can be seen that the device 1 is giving more output power as compare to device 2. So for high output power application device 1 can be preferred. Both devices shows a slightly downward shift of the curve i.e. decrease in output power as number of well is increasing. The difference in the output power can be due to the light scattering from the surfaces.

Fig 6 shows the spontaneous rate at different wavelength for Device 1 and Device 2. These figures depicts that as number of well is increased the spontaneous rate decreases. In case of device 1 the peak wavelength achieved is $0.410 \mu \mathrm{m}$ while in case of device 2 it is $\sim 0.435 \mu \mathrm{m}$. From the results it is depicted that device with higher In-concentration produce higher wavelength and thus are highly suited for solid state lighting.

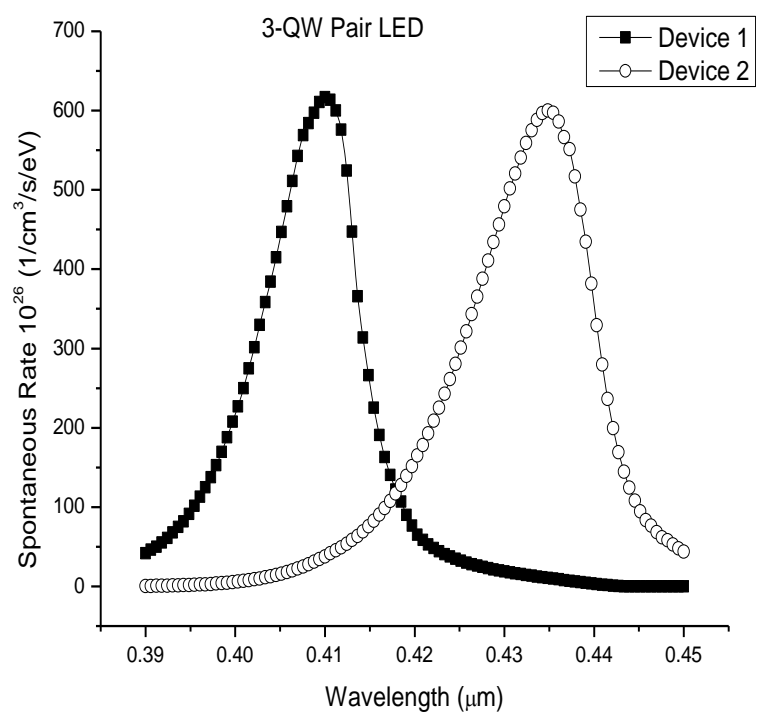

Fig 6(a) Spontaneous rate vs wavelength comparison of 3QW Pair LED Device 1 and Device 2 


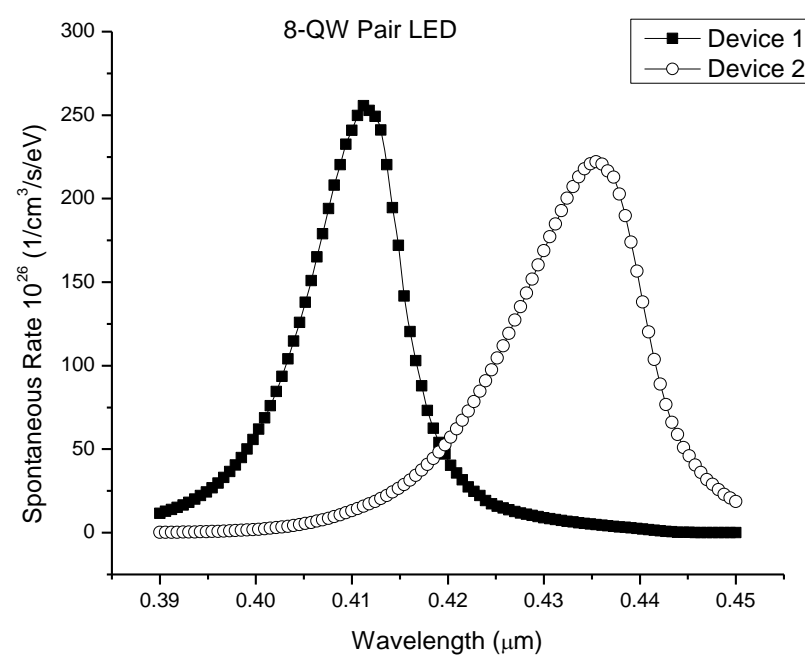

Fig 6(b) Spontaneous rate vs wavelength comparison of 8QW Pair LED Device 1 and Device 2

Table 2 Comparison of different parameters of Device 1 and Device 2

\begin{tabular}{|c|c|c|c|c|c|c|}
\hline & \multicolumn{2}{|c|}{$\begin{array}{c}\text { Turn on } \\
\text { Voltage (V) }\end{array}$} & \multicolumn{2}{|c|}{$\begin{array}{c}\text { Efficiency at } \\
\text { current } \\
500 \mathrm{~A} / \mathrm{m} \\
(\%)\end{array}$} & \multicolumn{2}{|c|}{$\begin{array}{c}\text { Output Power } \\
\text { at current } \\
500 A / m \\
(\text { Watt } / \mathbf{m})\end{array}$} \\
\hline & $\begin{array}{c}\text { 3- } \\
\text { QW }\end{array}$ & $\begin{array}{c}\text { 8- } \\
\text { QW }\end{array}$ & $\begin{array}{c}\text { 3- } \\
\text { QW }\end{array}$ & $\begin{array}{c}\text { 8- } \\
\text { QW }\end{array}$ & 3-QW & 8-QW \\
\hline $\begin{array}{c}\text { Device } 1 \\
\left(\mathrm{In}_{0.15} \mathrm{Ga}_{0.8}\right. \\
{ }_{5} \mathrm{~N} / \mathbf{I n G a N} \\
\text { LED) }\end{array}$ & $\begin{array}{c}2.87 \\
8\end{array}$ & $\begin{array}{c}2.86 \\
2\end{array}$ & $\begin{array}{c}98.58 \\
3\end{array}$ & $\begin{array}{c}97.92 \\
7\end{array}$ & $\begin{array}{c}1497 . \\
81\end{array}$ & $\begin{array}{c}1481 . \\
36\end{array}$ \\
\hline $\begin{array}{c}\text { Device } 2 \\
\left(\mathbf{I n}_{0.2} \mathbf{G a}_{0.8}\right. \\
\text { N/ InGaN } \\
\text { LED) }\end{array}$ & $\begin{array}{c}3.11 \\
4\end{array}$ & $\begin{array}{c}3.12 \\
4\end{array}$ & $\begin{array}{c}98.31 \\
5\end{array}$ & $\begin{array}{c}97.99 \\
8\end{array}$ & $\begin{array}{c}1414 . \\
51\end{array}$ & $\begin{array}{c}1408 . \\
12\end{array}$ \\
\hline
\end{tabular}

From Table 2 it can be seen that the device 1 has achieved more efficiency at high current $(98.58 \%)$ for 3-QW pair and in case of 8-QW pair both devices achieved $\sim 97.9 \%$ so device 1 with 3QW pair can be used in the applications where efficiency is the first priority. Device 1 is also giving more output power both in 3-QW pair ( 1497 w/m) and 8-QW pair ( $1481 \mathrm{w} / \mathrm{m})$.

\section{CONCLUSION}

From the study it can be investigated that both the devices are giving output in same frequency range, the peak wavelength of device $1(\sim 410 \mathrm{~nm})$ and of device $2(\sim 430 \mathrm{~nm})$ lie in the same range. The device 2 shows more shift towards blue range. The device 1 achieves its maximum efficiency $(\sim 98.58 \%)$ with 3 QW pair while device 2 achieves its maximum efficiency $(\sim 98.56 \%)$ with $1-\mathrm{QW}$ at high current. Also, by varying the concentration of Indium in $\operatorname{In}_{\mathrm{X}} \mathrm{Ga}_{1-\mathrm{X}} \mathrm{N}$ quantum well the variation in output wavelength is achieved and also turn on voltage is low for small value of $\mathrm{x}$. The result shows that the spectrum gets broaden because of the increase in Incomposition, also the blue shift is more. With increase in Incomposition the high efficiency will be achieved for less number of well and output power is also more than that of less In-ratio. Further study of parameters of the device can be done by varying thickness of the well and keeping number of well to be constant.

\section{ACKNOWLEDGEMENT}

APSYS software is provided by Crosslight Inc. for doing this work.

\section{REFERENCES}

[1] M. H. Kim, M. F. Schubert, Q. Dai, J. K. Kim, E. F. Schubert, J. Piprek, and Y. Park, "Origin of efficiency droop in GaN-based light-emitting diodes," Appl. Phys. Lett., vol. 91, no. 18, pp. 183507-1-183507-3, Oct. 2007.

[2] M. F. Schubert, J. Xu, J. K. Kim, E. F. Schubert, M. H. Kim, S. Yoon, S. M. Lee, C. Sone, T. Sakong, and Y. Park, "Polarization- matched GaInN/AlGaInN multiquantum-well light-emitting diodes with reduced efficiency droop," Appl. Phys. Lett., vol. 93, no. 4, pp. 041102-1-041102-3, Jul. 2008

[3] Y. C. Shen, G. O. Mueller, S. Watanabe, N. F. Gardner, A. Munkholm, and M. R. Krames, "Auger recombination in InGaN measured by photoluminescence," Appl. Phys. Lett., vol. 91, no. 14, pp. 141101-1-141101-3, Oct. 2007.

[4] J. Piprek, "Efficiency droop in nitride-based light-emitting diodes," Phys. Status Solidi (A), vol. 207, no. 10, pp. 2217-2225, Oct. 2010

[5] J. Hader, J. V. Moloney, and S. W. Koch, "Densityactivated defect recombination as a possible explanation for the efficiency droop in GaN-based diodes," Appl. Phys. Lett., vol. 96, no. 22, pp. 221106-1-221106-3, Jun. 2010.

[6] R. J. Choi, Y. B. Hahn, H. W. Shim, M. S. Han, E. K. Suh, and H. J. Lee, "Efficient blue light-emitting diodes with InGaN/GaN triangular shaped multiple quantum wells," Appl. Phys. Lett., vol. 82, no. 17, pp. 2764-2766, Apr. 2003.

[7] A. J. Ghazai, S. M. Thahab, H. A. Hassan, and Z. Hassan, "Quaternary ultraviolet AlInGaN MQW laser diode performance using quaternary AlInGaN electron blocking layer," Opt. Exp., vol. 19, no. 10, pp. 9245-9254, May 2011.

[8] X. Ni, Q. Fan, R. Shimada, Ü. Özgür, and H. Morkoç, "Reduction of efficiency droop in InGaN light emitting diodes by coupled quantum wells," Appl. Phys. Lett., vol. 93, no. 17, pp. 171113-1-171113-3, Oct. 2008.

[9] S. H. Han, D. Y. Lee, S. J. Lee, C. Y. Cho, M. K. Kwon, S. P. Lee, D. Y. Noh, D. J. Kim, Y. C. Kim, and S. J. Park, "Effect of electron blocking layer on efficiency droop in InGaN/GaN multiple quantum well light-emitting diodes," Appl. Phys. Lett., vol. 94, no. 23, pp. 231123-1-231123-3, Jun. 2009.

[10] S. F. Chichibu, T. Sota, K. Wada, O. Brandt, K. H. Ploog, S. P. DenBaars, and S. Nakamura, "Impact of internal electric field and localization effect on quantum well excitons in $\mathrm{AlGaN} / \mathrm{GaN} / \mathrm{InGaN}$ light emitting diodes," Phys. Status Solidi (A), vol. 183, no. 1, pp. 91-98, Jan. 2001.

[11] J. Iveland, L. Martinelli, J. Peretti, J. S. Speck, and C. Weisbuch, "Direct measurement of auger electrons emitted from a semiconductor light emitting diode under electrical injection: Identification of the dominant mechanism for efficiency droop," Phys. Rev. Lett., vol. 110, no. 17, pp. 177406-1-177406-3, Apr. 2013. 
[12] C. K. Tan, J. Zhang, X. H. Li, G. Liu, B. O. Tayo, and N Tansu, "First principle electronic properties of dilute-As GaNAs alloy for visible light emitters," J. Display Technol., vol. 9, no. 4, pp. 272-279, Apr. 2013.

[13] APSYS by Crosslight Software Inc. Burnaby, Canada [Online]. Available: http://www.crosslight.com.
[14] O. Ambacher "Growth and applications of group IIInitrides", J. Phys. D: Appl. Phys.,vol. 31, no. 20, pp. 26532710, June 1998.

[15] C. Trager-Cowan "Report on the evening rump session on InN - July 21, 2004 at the 2004 International Workshop on Nitride Semiconductors", Phys. Status Solidi, vol.2, no. 7, pp. 2240-2245, May 2005. 